RESUMO
O presente artigo tem por tema
a função do luto na constituição
do desejo. A partir da experiên-
cia clinica com 'idosos', sua pro-
blemática consiste em delinear o
trabalho de luto convocado pela
perda, localizando em um tem-
po de estruturação subjetiva as
operações de alienação e separa-
ção. Situa-se a perda que é bus-
cada na operação de separação
e que implica um luto primor-
dial. Seguindo indicações de
Jacques Lacan, o Hamlet de
Shakespeare, com a morte de
Ophelia, permite afirmar que a
perda em jogo no luto é da or-
dem da privação e requer tra-
balho para situar-se do lado da
castração.
Descritores: psicanálise;
luto; privação; castração; de-
sejo.

\section{A FUNÇÃO \\ CONSTITUTIVA DO LUTO NA ESTRUTURAÇÃO DO DESEJO}

Glória Castilho Angélica Bastos

Mãitina era pessoa para qualquer hora falar no Dito e por ele começar a chorar.... Escondido, escolheram um recanto, debaixo do jenipapeiro, ali abriram um buraco,

cova pequena. De em de, camisinha e calça do Dito furtaram, para enterrar, com brinquedos dele....

Miguilim tinha todas as lágrimas nos olhos...

Guimarães Rosa

\\}

ão pregnante na clínica com 'idosos', ${ }^{1}$ a questão do luto atravessa qualquer análise, na medida em que a perda é estruturante e concerne à dimensão infantil própria ao inconsciente enquanto tal. O presente trabalho busca situar a articulação da função do luto,

- Psicanalista, membro da Escola de Psicanálise Letra Freudiana, integrante da equipe clínica do Núcleo de Atenção ao Idoso (NAI/UnATI) da Universidade do Estado do Rio de Janeiro (UERJ), Rio de Janeiro, RJ, Brasil.

- 1 Psicanalista, professora no Programa de Pós-Graduação em Teoria Psicanalítica da Universidade Federal do Rio de Janeiro (UFRJ), bolsista de produtividade em pesquisa do Conselho Nacional de Desenvolvimento Científico e Tecnológico (CNPq), Rio de 
como estrutura fundamental da constituição do desejo, com a dimensão da experiência do luto em uma análise.

Parte-se da premissa freudiana segundo a qual o objeto desde sempre perdido é condição do desejo, o que confere ao luto função constitutiva dos circuitos desejantes na vida do falante: 'criança', 'adulto' ou 'idoso'. A perda de alguém amado, da qual se vem falar ao analista, por sua vez, é um acontecimento. Ela atualiza a estrutura e requer um trabalho de luto específico, voltado para aquele objeto, a fim de que - ao invés da inibição, da depressão, da inércia psíquica - a experiência da análise possa contar com os recursos da estrutura diante da contingência da perda de alguém ou algo intensamente investido. O luto constitutivo da estrutura do desejo não dispensa o sujeito do trabalho de luto ao longo da vida. Justamente porque o luto fundamenta a estrutura do desejo, um novo luto é convocado sempre que a perda se interpõe e, quando não é atravessado, os caminhos do desejo se obstruem, o que significa dizer que são duas ordens de luto, mas estrutura e experiência são dimensões articuladas. Procura-se mostrar, portanto, como - dada a função estruturante do luto - a cada perda vivida é o trabalho de luto do objeto que reabre as vias desejantes.

De modo recorrente, a queixa de 'idosos' em análise gira em torno das inúmeras e não raro concomitantes perdas significativas que relatam ter sofrido. Por vezes, trata-se da perda de um filho amado e/ou do cônjuge, companheiro de toda uma vida. Frente à magnitude das perdas impostas por acontecimentos deste porte, é comum a presença do seguinte relato: "É como se tivessem arrancado um pedaço meu: um braço, uma perna", frase que situa a afirmação de Freud de que a perda de alguém amado é vivida como perda no próprio eu (Freud, 1915/1996) e convoca a um trabalho que requer e implica tempo para que seja possível ressituar o campo narcísico e, também, o rodeio (Freud, 1900/1989a, p. 558) próprio ao desejo: o trabalho de luto.

Em $O$ desejo e sua interpretação (1958-1959) e, sobretudo, no seminário 10, A angústia (2006), Lacan procura indicar a função constitutiva do trabalho de luto na estruturação do desejo. Na direção de melhor precisar este nexo entre desejo e luto, partimos - em um tempo de estruturação subjetiva - das operações de alienação e separação, visando a localizar uma dimensão de perda que é buscada na operação de separação e que implica um luto primordial. Seguimos procurando situar, com Hamlet - da peça homônima de Shakespeare (1601/1984) - frente à perda de Ophelia, que a perda no luto, tal como se atualiza ao longo da existência, é para Lacan (1958-1959) da ordem da privação, exigindo trabalho para aceder à castração. 


\section{A perda buscada e a perda no luto}

Lacan (1998a) afirma que "uma estrutura quadripartite, desde o inconsciente, é sempre exigível na construção de uma ordenação subjetiva" (p. 785). Nesta direção, aponta a importância de que se opere - em termos estruturais mínimos - com a vigência do sujeito dividido e do campo do objeto no intervalo entre dois significantes. Em torno do que lhe apresenta seu neto de um ano e seis meses, Freud (1920/1989b), demarca dois significantes: "fort" e "da" (pp. 14-15), e no intervalo o sujeito às voltas com um carretel e o incansável esforço de lançá-lo à distância, raramente sucedido pela alegria frente à sua reaparição, que constituía a brincadeira completa. Interessa voltar ao "fort" - " da" freudiano, sobretudo agregando aí a nota de rodapé na qual Freud relata que, ao chegar à sua casa, a mãe encontra o bebê brincando ativamente frente a um espelho que lhe permitia, ao abaixar-se e levantar-se, fazer desaparecer sua própria imagem. Há aí uma encenação da própria desaparição, em uma perda ativamente buscada que Lacan (1979) situa como estruturante. Por esta via, formula questões que delimitam as operações lógicas circulares, mas não recíprocas de alienação e separação: como o sujeito se introduz na cadeia significante? Como se demarca o campo do objeto? Para encaminhar tais questões, Lacan recorre a operações da lógica dos conjuntos - reunião e interseção - que lhe permitem ressaltar a participação da perda como constitutiva, como estruturante.

\section{ALIENAÇÃO-REUNIÃO}
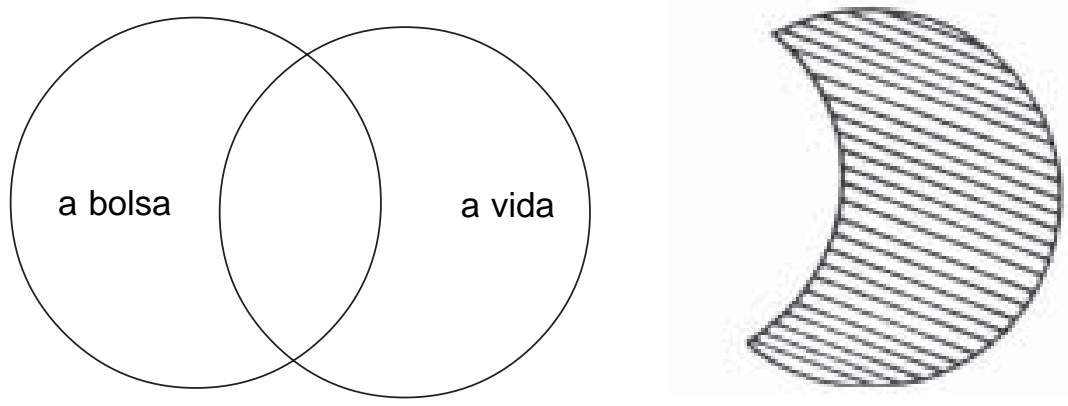

Figura 1 


\section{SUJEITO OUTRO}

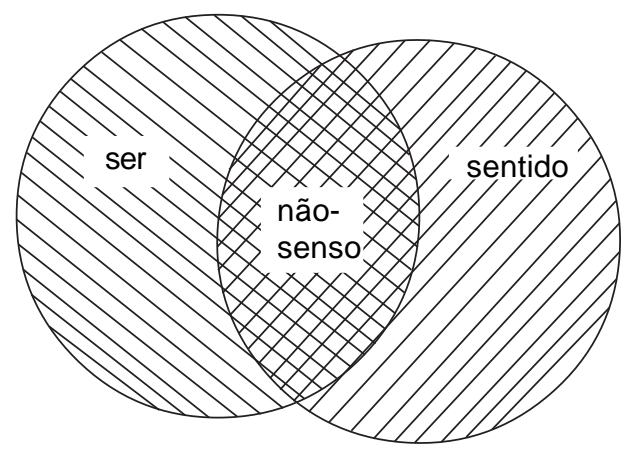

Figura 2

Com respeito à alienação - e à afânise ${ }^{2}$ como efeito -, Lacan (1979) recorre à operação de reunião e demarca que não se trata aí da soma dos elementos e sim de localizar a perda, ou seja, entre o ser e o sentido a escolha é forçada e implica perda (figura 2). Ali onde o que se apresenta como via única é a vida sem a bolsa (figura 1) ou o sentido decepado de uma parte do ser. Vejamos o que diz Lacan: "O sujeito nasce no que, no campo do Outro, surge o significante. Mas por este fato mesmo, isto - que antes não era nada senão sujeito por vir - se coagula em significante" ( $p$. 187). A consequência neste ponto é a afânise como um efeito, já que a operação de alienação reduz "o sujeito em instância a não ser mais do que um significante, petrificando-o pelo mesmo movimento que o chama a funcionar, a falar como sujeito" (p. 197). O sujeito é, portanto, afanisado "só - depois" pelo significante binário. Assim, neste primeiro tempo da alienação o sujeito está desaparecido, afanisado sob os significantes que o representam. Não tem outra substância que a de ser o que um significante representa para outro significante. Esta é sua carência, sua falta a ser, assinala Lacan.

Sobre a separação e a "função afânise", o fato novo introduzido por Lacan (1979) - ao abordar a estruturação subjetiva pelo viés das operações de alienação e separação encontra-se, sobretudo, do lado da operação de separação, que visa àquilo que no intervalo entre significantes relança duas faltas que se recobrem na constituição do desejo como desejo do Outro. Lançando mão da etimologia, Lacan (1979) assinala estar em jogo no termo separação separare, se parare, se parer, se parere um campo semântico que desdobra direções que incluem tanto separarse como parir-se, vestir-se, defenderse ou engendrar-se e nos permite apreender o quanto o sujeito encontra-se concernido na operação de separação. 


\section{SEPARAÇÃO-INTERSECÇÃO}

\section{SUJEITO OUTRO}
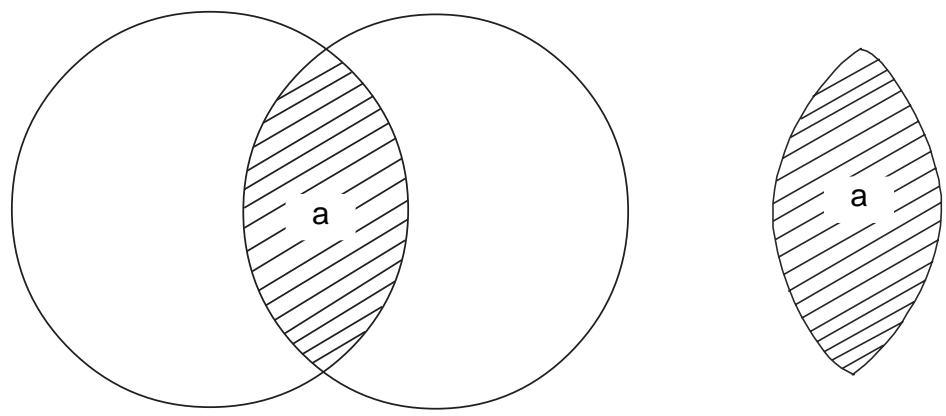

Figura 3

$\mathrm{Na}$ dialética das relações entre o sujeito e o Outro vão sendo recortadas as zonas erógenas, sob o comando do complexo de castração: no desmame, na separação das fezes, da mãe ao nascer. Trata-se aí de um mapeamento libidinal, fragmentário, que escapa ao campo especular, ao campo narcísico. Sigamos Freud (1923/ 1989c):

Com acerto se assinalou que a criança adquire a representação de um dano narcísico por perda corporal, mediante a perda do peito materno após sugá-lo, da cotidiana deposição das fezes e até da separação do ventre da mãe ao nascer. Não obstante, só cabe falar de um complexo de castração quando essa representação de uma perda se enlaçou aos genitais masculinos. (pp. 147-148)

Desta forma, o complexo de castração - operando desde o campo do Outro - ordena a relação à demanda oral, anal e, como assinala Freud (1924/1989d), a "ameaça de castra- ção obtém seu efeito a posteriori (Nachträglich)" (p. 183). Lacan (2006) chama a atenção para o fato de que, diferentemente de uma perspectiva desenvolvimentista - tal como situada por Abraham -, o objeto $a^{3}$ (figura 3) apresenta-se como função, que se mantém a cada passagem, de um modo a outro de relação à demanda do Outro e, sob "as diversas formas em que ele se manifesta, trata-se sempre de uma mesma função" (pp. 320321). É assim que, operando com o mito da libido como lâmina, órgão irreal que corta e recorta, Lacan (1979) delimita quatro modalidades de apresentação do objeto $a$, acrescentando ao seio e às fezes, a voz e o olhar. Importa, sobretudo, o que se recorta, o que se produz a partir do corte. No esforço de situar a especificidade do objeto $a$, Lacan (1979) toma como exemplar o seio na pulsão oral e aponta que o objeto $a$ não é a 
origem desta pulsão - ele "é introduzido pelo fato de que nenhum alimento jamais satisfará a pulsão oral, senão contornando-se o objeto eternamente faltante" (p. 170).

Ainda com relação ao objeto oral, Lacan (2006) interroga: de que lado está o seio? Do lado daquele que suga ou do lado do que é sugado? De quem é o seio? Nem da mãe... nem da criança. Daí, inclusive, todas as dificuldades com a amamentação. O acento é colocado "entre-dois", no desmame. A mãe - em função - que cuida, demanda e para além da demanda ... deseja, é apreendida como enigmática: "Ela me diz que coma, mas, 'o que ela quer"? Entre os significantes da demanda, diz Lacan (1979), corre, esconde-se o desejo do Outro, "apreendido pelo sujeito naquilo que não cola, nas faltas do discurso do outro" (p. 203). É apenas no intervalo, para além da demanda, portanto, que pode insinuar-se um desejo enigmático, que também o Outro desconhece e que, por esta via, abre à dimensão do equívoco. Cabe sublinhar que este encontro com o desejo do Outro permite relativizar a demanda do Outro. Lacan exemplifica com os infindáveis "por quês? da criança" (p. 203) que visam - em última instância - a situar o enigma do desejo do adulto.

Importa situar e diferenciar aí uma dimensão de perda que é buscada, na medida em que se insinua que, ao Outro, algo falta. Lacan (2006) pontua que o "Outro concerne a meu desejo na medida do que lhe falta e de que ele não sabe ... porque, para mim, não há outro desvio para descobrir o que me falta como objeto do meu desejo" (pp. 32-33). Lacan (1979) assinala um tempo na estruturação subjetiva que implica o recobrimento de duas faltas: a falta do sujeito afanisado, própria da operação de alienação, e a falta do Outro, falta esta que se insinua para além da demanda, descortinando algo do desejo como desejo do Outro. Como o sujeito se situa com relação à falta apreendida no Outro? Frente à pergunta: "ele me diz isso, mas o que é que ele quer?’ (p. 203), apresenta-se, então, a questão da perda: quer a minha perda?

Para sustentar sua argumentação, Lacan lança mão de uma figura do folclore europeu. Trata-se de Gribonille, que, como esclarece Heinrich (1996), funciona de uma forma muito própria frente ao que se lhe apresenta. Ao encontrar um cortejo fúnebre, Gribouille parabeniza a todos e é fortemente repreendido, já que a ocasião pede pêsames e não congratulações. Seguindo seu caminho, Gribouille encontra agora um cortejo nupcial e aproxima-se consternado de- 
sejando a todos seus pêsames. Novamente é repreendido, pois não cabe ali, em um momento de grande alegria, seu pesar. Lacan (1979) comenta que o sujeito responde como Gribonille, ou seja, "o sujeito traz a resposta da falta antecedente de seu próprio desaparecimento, que ele vem aqui situar no ponto da falta percebida no Outro" (p. 203). Neste ponto de virada, é preciso assinalar a incidência de uma perda que passa a ser buscada. Acompanhemos Lacan: "O primeiro objeto que ele propõe a esse desejo parental cujo objeto é desconhecido é sua própria perda - "Pode ele me perder? A fantasia de sua morte, de seu desaparecimento, é o primeiro objeto que o sujeito tem a pôr em jogo nessa dialética" (p. 203), fantasma comumente acionado nas relações de amor entre a criança e seus pais.

É preciso ressaltar que Lacan (1979) faz referência à "função afânise" (p. 215), diferenciando-a da afânise que, em um primeiro tempo, havia sido configurada como efeito da operação de alienação. Heinrich (1996) situa que agora a afânise "deve ser posta em jogo como função” (p. 33) que permitirá interrogar o desejo do Outro: "Pode ele me perder?" (Lacan, 1979, p. 203). Cabe assinalar que, em "Posição do inconsciente", Lacan (1998b), voltando às operações de alienação e separação, ressalta com relação à separação que "se trata aí de um querer" (p. 857), indicando a atividade em jogo na operação de separação. ${ }^{4}$ Por esta via, há uma passa- 
gem de desaparecido a perdido que requer uma ratificação do Outro, ou seja, a identificação ao falo imaginário - ser aquilo que falta ao Outro como um tempo lógico necessário que permite fazer o luto por este lugar mítico, desde sempre perdido.

É assim que a criança, após assistir com seus pais a uma sessão do documentário $A$ marcha dos pinguins, dirigido por Luc Jacquet (2005) e rodado no sudeste da Antártida, formula uma questão que interessa por sua precisão. O filme acompanha a inóspita saga do pinguim-imperador pelas gélidas regiões em que é forçado a atravessar para chegar ao local onde ocorrerá a procriação. A fêmea faz todo o percurso de volta em busca de alimento e o pinguim macho fica encarregado de chocar o ovo, que está sendo resguardado. Esta operação exige toda uma perícia por parte do pinguim macho, que aconchega o ovo entre suas patas e o ventre, para que obtenha um mínimo de calor, já que o contato direto com o gelo inviabilizaria o nascimento da cria. Ocorre que a filmagem testemunha uma situação súbita, em que o ovo se desprende e cai no gelo. A reação do pinguim macho é imediata - sem mediação possível -, precipitando-se sobre outro pinguim, em um claro esforço de arrancar-lhe o ovo aninhado. Este comportamento desencadeia, no bando, um movimento generalizado para proteger o pinguim e seu ovo, atacados pelo pinguim agressor. Após a sessão de cinema, a criança formula - dirigida ao pai - a seguinte pergunta: "Se eu morresse, você arrancaria outra criança dos braços do pai?" Obteve como resposta, não sem um toque de humor: "Meu filho, eu não sou um pinguim.” A acuidade da pergunta e da resposta situa a importância para o ser falante de que lhe seja outorgado um lugar, passível de ser ocupado, mas, em última instância, lugar vazio, aberto à mediação do trabalho de luto, a partir da perda. Por esta via constitui-se o lugar do desejo, ou seja, a partir do luto primordial, pela identificação a esse lugar do objeto, desde sempre perdido.

\section{Hamlet e a questão do luto}

O comentário de Lacan (19581959, 2006) acerca do luto gira, em várias oportunidades, em torno de Hamlet, personagem da peça de Shakespeare (1601/1984) de mesmo nome, sobretudo, em torno da cena do cemitério onde ocorre o enterro de Ophelia. Vejamos alguns elementos da cena.

Hamlet retorna de viagem e, junto com Horacius, ao passar pelo cemitério, percebe estar sendo preparada uma cova para um enterro. Aproximam-se do coveiro e Hamlet procura indagar quem será enterrado. O coveiro responde com alusões e evasivas. Mantém-se, assim, um pouco mais em cena a pergunta acerca de 
quem teria morrido. Revela, de passagem, a identidade de um homem cujo crânio exibia, causando a Hamlet comoção por tratar-se do bobo da corte que, em sua infância, esteve muito presente. Neste ínterim, começa a aproximar-se o cortejo fúnebre; Hamlet esconde-se e vislumbra o rei, a rainha - sua mãe e várias figuras da corte. Percebe, então, tratar-se de Ophelia, que vem carregada para ser enterrada. $\mathrm{Na}$ sequência, iniciam-se as despedidas fúnebres e, dentre elas, Laertes, em uma atitude de desespero, lança-se sobre sua irmã Ophelia morta, lamuriando-se e chorando convulsivamente. Neste ponto, Hamlet revela-se e precipita-se sobre Laertes, interrogando a propriedade de tamanha dor, já que ele, Hamlet, encontrava-se atravessado por uma dor que não poderia ser menor que a de um irmão.

Rabinovich (1993) procura esclarecer o problema com que se defronta Lacan (2006) ao examinar a cena do cemitério e explica que se trata de diferenciar o falo e o objeto do desejo que se articulam no agalma. ${ }^{5}$ Pondera que agora, em $A$ angústia, não se trata do agalma, e sim de algo muito diferente, pois, quando fala do objeto do desejo, Lacan (2006) remete ao luto. Comenta que Lacan relaciona "a identificação com o objeto do desejo, com o mecanismo próprio do luto, não o da melancolia, senão o mecanismo próprio do luto normal” (p. 58). Interrogase, com relação a esta afirmação, se Lacan estaria dizendo algo novo acerca do luto e, para sustentar afirmativamente sua resposta, reporta-se aos comentários de Lacan (1958-1959) que assinalam estar em jogo no luto não a castração, mas a privação. Para Lacan (1992), a privação é a falta real de um objeto simbólico, a frustração é a falta imaginária de um objeto real e a castração é a falta simbólica de um objeto imaginário. É na medida em que a tríade Privação-Frustração-Castração refere-se aos avatares da falta de objeto que nos interessa aqui retomá-la. Nesta direção, Lacan (2006) situará a função do luto demarcando aí a "estrutura fundamental da constituição do desejo" (p. 361).

Lacan (2006) interroga-se acerca do que permite a Hamlet sair da inibição ${ }^{6}$ e realizar o ato que lhe concerne. Esta dificuldade se apresenta desde que Hamlet é incumbido, pelo espectro de seu pai, de matar seu tio Claudius, que - conforme revelado - assassinou seu pai e casou-se com sua mãe. Rabinovich (1993) afirma que Lacan enfrenta aí um problema clínico, pois 
"o falo não oferece a resposta que permite a saída da inibição; essa resposta a oferece o objeto" (p. 58). Trata-se, neste ponto, de uma identificação que Lacan (2006) qualifica de "mais misteriosa" (p. 46): a identificação com o lugar do objeto como objeto perdido.

É exatamente aí que a cena do cemitério ganha todo o seu alcance. A manifestação ostensiva da dor de Laertes, pela perda de sua irmã Ophelia, ressitua para Hamlet o objeto do desejo que terá sido Ophelia. Lacan (2006) chama a atenção para a importância de Laertes como duplo, i'(a), já que força Hamlet a sintonizar com a questão do desejo, ainda que não permita sua saída da inibição.

Desse modo, Rabinovich (1993) assinala, seguindo Lacan, que a identificação com Ophelia "não é a identificação com um par, um rival, com um semelhante, é a identificação com o objeto como perdido" (p. 59). Neste ponto, esclarece e sublinha que "toda identificação na ordem do especular exclui a falta ... exclui a perda constitutiva do objeto" (p. 59). Daí que, como rival, i'(a), o sujeito não chega a situar sua posição como causa de desejo do Outro. Já Ophelia, em outra direção, transmite a Hamlet, através de seu ato suicida, algo como "se tu não estás a vida não é nada para mim” (p. 64). Há, neste ponto, uma consequência muito importante com respeito à relação entre objeto e desejo, já que para que alguém se torne objeto, para que possa "ocupar o lu- 
gar do que causa o desejo do Outro, só uma vez que o Outro o perdeu" (p. 59).

É apenas diante da tumba que Hamlet se dá conta da desaparição de Ophelia, cujo desejo ele sabia que causava. Por ser causa desse desejo, Ophelia torna-se ela própria, para Hamlet, objeto de seu desejo, na medida em que "o desejo é sempre desejo do desejante no Outro" (p. 64) Por este viés, havendo ressituado seu desejo, identificando-se com o lugar do objeto perdido - identificação que remete "ao vazio, ao buraco no $\mathrm{Ou}$ tro” (p. 64) -, Hamlet está em condições de realizar o ato que lhe concerne, saindo da inibição.

Reside aí um aspecto crucial da peça: a ausência do luto da mãe de Hamlet pela morte de seu pai. Evidencia-se, para Hamlet, que seu pai não ocupava para sua mãe um lugar de causa de desejo, já que não teria havido ali perda capaz de convocá-la ao trabalho de luto, que requer tempo. Lacan (1958-1959) chama a atenção para a frase de Hamlet, segundo a qual as sobras da refeição fúnebre teriam servido para a refeição das núpcias, ou seja, não teria havido tempo hábil para o trabalho de luto.

Rabinovich (1993) comenta que Lacan é aí estritamente freudiano ao sustentar que apenas na perda se constitui o objeto em sua relação com o desejo. Reporta-se ao Adendo C "Angústia, dor e luto", do texto "Inibição, sintoma e angústia", em que Freud (1926/1989e) procura situar as diferentes formas da perda, articulando-a ao luto, à angústia e à dor. Tratase de uma importante referência se comparada à leitura de Allouch (2004) acerca do trabalho de luto em Freud, para quem, segundo Allouch, sempre haveria substituição ao final do trabalho de luto. Allouch insiste sobre o caráter insubstituível do objeto no luto, afirmando que este, em sua radicalidade, implica algo de uma "perda seca" (p. 144), que não seria passível de substituição. Para sustentar seu argumento, reporta-se todo o tempo a "Luto e melancolia" (Freud, 1917/1989f), em que a ênfase na substituição do objeto, ao final do trabalho de luto, encontra-se presente.

Concordamos com Allouch (2004) e Rabinovich (1993) quanto ao fato de que cada luto, efetivamente, comporta algo de insubstituível. Consideramos importante situar este aspecto a partir dos relatos em análise de 'idosos'. A magnitude das perdas, tal como a perda de um companheiro de toda a vida ou a morte de um filho, convocam com muita frequência esta dimensão de que não há substituição possível. Rabinovich assinala que a

falta que provoca um sujeito falante não é substituível em certo ponto; nesse ponto onde fomos, nós mesmos, causa do desejo para esse Outro que já não está. Poderemos ser causa de algum Outro, é certo, mas jamais exatamente do mesmo modo. (1993, p. 61)

Conclui sua avaliação apontando que, "por esta razão, nem todos 
os buracos são equivalentes nem podem substituir-se entre si, não são homogêneos" (p. 61). Daí que a referência ao adendo de Freud (1926/1989e), "Angústia, dor e luto", mostra-se fundamental. Trata-se de um momento distinto daquele em que foi escrito "Luto e melancolia". Ao afirmar que nem tudo na pulsão é sexual, libidinal, Freud (1920/1989b) transmite, permite apreender, que nem tudo é passível de substituição.

\section{Sob o comando da prova de realidade: a exigência de veicular uma falta}

Em “A negação", ao abordar a dimensão pulsional em um tempo de fundação, de estruturação, Freud (1925/1988) demarca a incidência de dois processos na formação do eu prazer originário: a afirmação (Behajung) e a expulsão (Ausstoâung), que resultam na partição primordial - em mim/fora de mim. O que resta excluído constitui o mal, o estranho. Freud retoma aí alguns elementos já antecipados desde 1895, em torno de algo que se subtrai ao juízo e que resta inassimilável. Vale lembrar que "A negação" é um texto posterior à afirmação da pulsão de morte e da compulsão à repetição (Freud, 1920/1989b), bem como do supereu (Freud, 1923/1989g) e ainda do masoquismo originário (Freud, 1924/1989h). Situa-se, portanto, em um contexto em que o princípio do prazer implica o mais além do princípio do prazer, ou seja, implica a repetição de um esforço, sempre em fracasso, de ligar no solo do prazer aquilo que se apresenta como resto inassimilável.

É, portanto, neste enquadre que Freud (1925/1988) localiza, em um tempo originário, a função do juízo que se desdobra em "duas decisões" (p. 11): atribuição e existência. Avalia que a "experiência ensinou que não só importa se uma coisa (objeto da satisfação) possui a qualidade 'boa' e, portanto, merece a admissão no eu, mas também se ela existe no mundo de fora, de modo que possa apoderar-se dela" (p. 13). Pondera que, originalmente, a existência de uma representação já é "uma fiança para a realidade do representado" (p. 13), dado que a diferença entre objetivo e subjetivo não existiria desde o começo.

A propósito do significante fiança (Bürgschaft), Vidal (1988), chama a atenção para o fato de que a "prova de realidade instaura uma 
interpelação a nível da representação. Decidir sobre a existência é uma ação que não recai sobre a realidade do mundo exterior, mas, sobre a fiança a outorgar a uma representação" (p. 27). Freud (1925/ 1988) agrega que a diferença entre subjetivo e objetivo "somente se estabelece pelo fato de que o pensar possui a capacidade de tornar de novo presente, pela reprodução na representação, algo percebido uma vez, enquanto o objeto não precisa mais existir fora". Neste ponto, avalia que "o primeiro e mais imediato objetivo da prova de realidade não é encontrar na percepção real um objeto correspondente ao representado, mas reencontrá-lo, certificar-se de que ainda existe" (p. 13).

Avançando em sua argumentação, Freud (1925/1988) conclui que "se reconhece como condição para a instalação da prova de realidade que tenham sido perdidos os objetos que haviam trazido antigamente satisfação real” (p. 13), deixando clara aí a função da perda no trabalho que se desencadeia. Já em "Luto e melancolia" Freud (1917/1989f) afirmara a importância da prova de realidade no avanço do trabalho de luto peça por peça, forçando o desligamento dos laços com o objeto perdido. Vidal (1988) avalia, seguindo Freud, que a "prova de realidade exige e força a representação a encontrar sua única fiança: a de veicular uma falta. A prova de realidade trabalha na delimitação do buraco no simbólico” (p. 27).

A Verwerfung é invocada em contraposição ao buraco real próprio ao luto. Enquanto a primeira consiste em um significante rejeitado no simbólico que repercutirá seus efeitos de retorno no real, no segundo, o buraco real cavado pela perda mobilizará o simbólico, exigindo que a cadeia significante se movimente para nele demarcar a falta (Lacan, 1958-1959).

Situar a falta neste contexto permite retomar o nexo entre a perda buscada, intrínseca à operação constitutiva de separação, e a perda em jogo no luto tal como se apresenta ao longo da existência. No luto, é preciso trabalhar - sob o comando da prova de realidade - para perder, para delimitar o buraco no simbólico, trabalho que toca a dimensão primordial da perda. Nesta direção, cabe demarcar o que diz Lacan (1958-1959) acerca do luto como experiência do lado da privação: "A dimensão intolerável oferecida à experiência humana, não é a experiência da própria morte, que ninguém tem, mas a da morte de um outro" (p. 74). Trata-se de um comentário em sintonia com a posição de Freud (1915/1996) sobre a ausência de registro da própria morte no inconsciente. Em torno deste pon- 
to, Lacan (1958-1959) segue interrogando: "O buraco desta perda, que provoca no sujeito o luto, onde está ele? Ele está no real” (p. 74). Consideramos que precisar este aspecto no luto, dito normal, permite indicar que o trabalho de desligamento do objeto, comandado pela prova de realidade, chega a localizar a perda - ao final do trabalho de luto - do lado da castração, buraco no simbólico. $\mathrm{O}$ trabalho do luto, portanto, conduziria a perda à falta.

Importa demarcar, neste ponto, algumas distinções. Inicialmente, é preciso diferenciar aquelas situações referidas aos ideais - tais como a honra e a vingança invocadas pelo espectro do pai de Hamlet - das situações que tocam um ponto estrutural. É assim que, de um lado, assinala Rabinovich (1993), há uma dimensão de luto - cujo paradigma é o desmame - que consiste no luto pela perda como objeto de gozo, para que possa ser recuperado como causa de desejo: "O próprio sujeito como objeto de gozo ... deve perder essa posição ... para chegar a causar o desejo do Outro, para posicionarse na falta no Outro" (p. 63). Além disso - tal como indicado em Hamlet, a partir da perda de Ophelia -, é preciso situar o luto quando o Outro falta, "se perde o Outro, tem que fazer o luto pelo lugar mesmo de causa que ocupava em relação com a falta do Outro, com seu desejo" (p. 63).

\section{Para concluir}

Ao localizarmos o luto como um trabalho que se desdobra da privação à castração - ao longo do qual a perda é levada a ser demarcada como falta no simbólico - vale lembrar a orientação de Lacan (1998c) segundo a qual a "castração significa que é preciso que o gozo seja recusado, para que possa ser atingido na escala invertida da Lei do desejo" (p. 841). Trata-se de uma frase que, via castração, nos permite demarcar a função constitutiva do luto na estruturação do desejo. Esta indicação é fundamental na experiência analítica com 'idosos', fortemente marcada pela incidência de um doloroso trabalho de luto em um primeiro tempo de análise.

Apreendemos com Freud e Lacan que oferecer no jogo transferencial um lugar vazio - esvaziado de gozo - ao desejo do sujeito, "para que se realize como desejo do Outro" (Lacan, 1991, p. 128), permite recolocar em movimento o rodeio próprio ao dese- 
jo, que implica a castração. Por esta via, torna-se possível a aposta na tradução, para cada um, de uma pergunta em torno de alguma invenção (Lacan, 2007) ou, como diz Freud (1937/1986), uma "neocriação" (pp. 229-230) a partir do trabalho de análise, diante do tempo que resta. Questão própria a qualquer análise, mas que ao ocorrer em uma análise na velhice tinge-se de uma radicalidade própria.

THE CONSTITUTIVE ROLE OF MOURNING IN THE STRUCTURING OF DESIRE

ABSTRACT

The theme of this article is the role of grief in the constitution of desire. Based on the clinical experience with the 'elderly', the problematic here is to outline the process of mourning triggered by the loss, locating the alienation and separation operations in a time of subjective structuring. The loss that is retrieved from the operation of separation is situated, thus involving a primordial mourning. Following some indications of Jacques Lacan, Shakespeare's Hamlet, with the death of Ophelia, lead us to affirm that the loss involved in mourning is of the order of the privation and requires work to be on the side of castration.

Index terms: psychoanalysis; mourning; privation; castration; desire.

\section{LA FUNCIÓN CONSTITUTIVA DEL LUTO EN LA ESTRUCTURACIÓN DEL DESEO}

\section{REsumen}

El tema de este artículo aborda la función del luto en la constitución del deseo. A partir de la experiencia clínica con 'ancianos', su problemática consiste en delinear el trabajo del luto convocado por la pérdida, localizando en un tiempo de estructuración subjetiva las operaciones de alienación y separación. Se sitúa la pérdida que es buscada en la operación de separación y que implica un luto primordial. Siguiendo indicaciones de Jacques Lacan, el Hamlet de Shakespeare, con la muerte de Ophelia, permite afirmar que la pérdida en juego en el luto es como una privación y requiere de esfuerzo para situarse al lado de la castración.

Palabras clave: psicoanálisis; luto; privación; castración; deseo. 


\section{REFERENNCIAS}

Allouch, J. (2004). Erótica do luto no tempo da morte seca. Rio de Janeiro: Companhia de Freud.

Barros, L. M. (2005). Investigação sobre a questão do ato em psicanálise. Tese de Doutorado, Instituto de Psicologia, Universidade Federal do Rio de Janeiro, Rio de Janeiro.

Castilho, G. (2011). Velhice e luto: "Quem não arrisca não petisca". Experiência de saber, 30(43), 297-310.

Freud, S. (1977). Projeto para uma psicologia científica. In S. Freud, Edição standard brasileira das obras psicológicas completas de Sigmund Freud (J. Salomão, Trad., Vol. 1, pp. 323-446). Rio de Janeiro: Imago. (Trabalho original publicado em 1895)

Freud, S. (1986). Análisis terminable e interminable. In S. Freud, Obras completas de Sigmund Freud (J. L. Etcheverry, Trad., Vol. 23, pp. 211-254). Buenos Aires: Amorrortu. (Trabalho original publicado em 1937)

Freud, S. (1988). Die Verneinung (A negação). Revista da Letra Freudiana, 5, 8-15 (Trabalho original publicado em 1925)

Freud, S. (1989a). La interpretación de los sueños. In S. Freud, Obras completas de Sigmund Freud (J. L. Etcheverry, Trad., Vol. 5, pp. 345-714). Buenos Aires: Amorrortu. (Trabalho original publicado em 1900)

Freud, S. (1989b). Más allá del principio del placer. In S. Freud, Obras completas de Sigmund Freud (J. L. Etcheverry, Trad., Vol. 18, pp. 1-62). Buenos Aires: Amorrortu. (Trabalho original publicado em 1920)

Freud, S. (1989c). La organización genital infantil. In S. Freud, Obras completas de Sigmund Freud (J. L. Etcheverry, Trad., Vol. 19, pp. 141-149). Buenos Aires: Amorrortu. (Trabalho original publicado em 1923)

Freud, S. (1989d). El sepultamiento del complejo de Edipo. In S. Freud, Obras completas de Sigmund Freud (J. L. Etcheverry, Trad., Vol. 19, pp. 177-187). Buenos Aires:
Amorrortu. (Trabalho original publicado em 1924)

Freud, S. (1989e). Inhibicíon, síntoma, angustia. In S. Freud, Obras completas de Sigmund Freud (J. L. Etcheverry, Trad., Vol. 20, pp. 71-164). Buenos Aires: Amorrortu. (Trabalho original publicado em 1926)

Freud, S. (1989f). Duelo y melancolía. In S. Freud, Obras completas de Sigmund Freud (J. L. Etcheverry, Trad., Vol. 14, pp. 235-255). Buenos Aires: Amorrortu. (Trabalho original publicado em 1917)

Freud, S. (1989g). El Yo y el Ello. In S. Freud, Obras completas de Sigmund Freud (J. L. Etcheverry, Trad., Vol. 19, pp. 1-66). Buenos Aires: Amorrortu. (Trabalho original publicado em 1923)

Freud, S. (1989h). El problema económico del masoquismo. In S. Freud, Obras completas de Sigmund Freud (J. L. Etcheverry, Trad., Vol. 19, pp. 161-176). Buenos Aires: Amorrortu. (Trabalho original publicado em 1924)

Freud, S. (1996). Nossa atitude para com a morte. Reflexões para os tempos de guerra e morte. In S. Freud, Edição standard brasileira das obras psicológicas completas de Sigmund Freud (J. Salomão, Trad., Vol. 14, pp. 283-312). Rio de Janeiro: Imago. (Trabalho original publicado em 1915)

Heinrich, H. (1996). Cuando la neurosis no es de transferencia. Rosario: Homo Sapiens.

Jacquet, L. (Diretor). (2005). A marcha dos pinguins [DVD]. Paris, FR: Bonne Pioche.

Jones, E. (1997). Le développement précoce de la sexualité féminine. In E. Jones, Théorie et pratique de la psychanalyse (pp. 399411). Paris: Payot. (Trabalho original publicado em 1933)

Lacan, J. (1958-1959). O desejo e sua interpretação. Texto não publicado.

Lacan, J. (1979). O Seminário, livro 11: os quatro conceitos fundamentais da psicanálise (M. D. Magno, Trad.). Rio de Janeiro: Jorge Zahar. Lacan, J. (1986). Hamlet por Lacan. São Paulo: Escuta; Liubliú. 
Lacan, J. (1991). Le Seminaire, livre 8: le transfert. Paris: Seuil.

Lacan, J. (1992). O Seminário, livro 17: o avesso da psicanálise (A. Roitman, Trad.). Rio de Janeiro: Jorge Zahar.

Lacan, J. (1998a). Kant com Sade. In J. Lacan, Escritos (V. Ribeiro, Trad., pp. 776803). Rio de Janeiro: Jorge Zahar.

Lacan, J. (1998b). Posição do inconsciente. In J. Lacan, Escritos (V. Ribeiro, Trad., pp. 843-864). Rio de Janeiro: Jorge Zahar.

Lacan, J. (1998c). Subversão do sujeito e dialética do desejo. In J. Lacan, Escritos (V. Ribeiro, Trad., pp. 807-842). Rio de Janeiro: Jorge Zahar.

Lacan, J. (2006). O Seminário, livro 10: a angústia (V. Ribeiro, Trad.). Rio de Janeiro: Jorge Zahar.

Lacan, J. (2007). O Seminário, livro 23: o sinthoma (S. Laia, Trad.). Rio de Janeiro: Jorge Zahar.

Rabinovich, D. S. (1993). La angustia y el deseo del Otro. Buenos Aires: Manantial.

Shakespeare, W. (1984). Hamlet (G. C. Silos, Trad.). Rio de Janeiro: JB. (Trabalho original publicado em 1601)

Vidal, E. (1988). Comentários sobre Die Verneinung. Revista da Letra Freudiana, 5, 16-31.

\section{NOTAS}

1 Ao longo de todo o trabalho, utilizaremos apóstrofos no termo 'idoso' para indicar a dissimetria entre o idoso como categoria historicamente construída e o sujeito dividido da experiência analítica, confrontado com as questões - sempre singulares - colocadas pelo processo de envelhecimento.

2 O termo afânise, tomado de Jones por Lacan, refere-se à desaparição do sujeito e não à desaparição do desejo - como o situa Jones (1933/1997).

3 O objeto $a$ é abordado por Lacan (2006) como objeto causa de desejo a partir do seminário $A$ angústia. $\mathrm{O}$ autor procura aproximar-se de sua complexidade, referindo-o a uma dimensão de alteridade e situando-o a partir do corte, da separação e da perda. Sustenta a importância de diferenciar o objeto $a$ de qualquer objeto passível de troca, intercambiável e, nesta direção, indica quatro figurações, modalidades de apresentação do objeto a: o olhar, a voz, o seio e as fezes. Lacan (1979) afirma, no entanto, que a despeito de suas vestimentas imaginárias, este objeto "é a presença de um cavo, de um vazio" (p. 170).

4 Confira o artigo "Velhice e luto: 'quem não arrisca não petisca"'(Castilho, 2011), onde recortamos a importância de situar a pergunta em torno do trabalho de luto na velhice - que implica o sujeito -, articulada à pergunta acerca de como intervir em uma economia de gozo, incluindo aí a função desejo do analista.

5 Em $A$ transferência, Lacan fala do agalma ao abordar a relação de Alcibíades com Sócrates, no Banquete. É como invólucro daquilo que é o objeto de desejo que Sócrates é apresentado. Lacan (1991) aponta que o "agalma bem pode querer 
dizer ornamento ou enfeite, mas, aqui, antes de mais nada, jóia, objeto precioso - algo que está no interior" (p. 141). Assim, o objeto em sua face agalmática é o objeto buscado, central na lógica amorosa.

6 Freud (1926/1989e) faz uma distinção entre a inibição geral do eu que ocorre, por exemplo, nos estados depressivos próprios ao luto e a inibição quanto a um ato específico, como ocorre com Hamlet. Sobre esta distinção em Hamlet, confira Barros (2005).

gloria.castilho@gmail.com

Av. Lineu de Paula Machado, 850/204 22470-040 - Rio de Janeiro - RJ - Brasil.

abastosg@terra.com.br Avenida Atlântica, 554/902 22010-000 - Rio de Janeiro - RJ - Brasil.

Recebido em maio/2012. Aceito em novembro/2012.

106 Estilos clin., São Paulo, v. 18, n. 1, jan./abr. 2013, 89-106. 